Brief Report

\title{
COMPARATIVE ANATOMICAL STUDIES ON SCAPULA OF COMMON PALM CIVET CAT (PARADOXURUS HERMAPHRODITUS) AND DOG (CANIS LUPUS FAMILIARIS)
}

\author{
Choudhary KBD and Anil Deka* \\ Department of Anatomy \& Histology, Assam Agricultural University, India
}

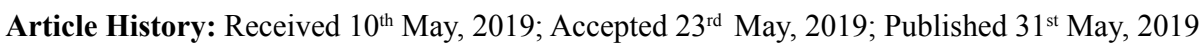

\begin{abstract}
In present studies, one pair of scapula of Common palm civet cat and Dog was utilized. The sizes of the supraspinous and infraspinous fosse were small compared to the fosse of scapula of Common palm civet cat. The size of the rough area of the scapular spine of Common palm civet cat was larger compared to the size of the rough area of the scapular spine of dog. The sub scapular fosse of the scapula of Dog (Canis lupus familiaris) was more deep compared to the scapula of Common palm civet cat. The depths of glenoid cavity and glenoid notch of scapula of Common palm civet cat were more compared to the scapula of the dog. The neck of the scapula of Dog (Canis lupus familiaris) was less constricted compared to the scapula of Common palm civet cat (Paradoxurus hermaphroditus). The scapular index of Common palm civet cat was less compared to the scapula of dog.
\end{abstract}

Keywords: Comparative; Anatomy, Scapula; Common palm civet cat; Dog

\section{INTRODUCTION}

The common palm civet cat (Paradoxurus hermaphrodites) is schedule-II animal as per the wild life protection Act, 1972. The family of the Common palm civet cat is Viverridae. They are nocturnal animal, arboreal and solitary. Their population is decrease due to habitat loss. They are mainly fond of fruit and honey, and found in most of the non-Himalayan India except the arid west (Menon, 2003). The dog is the first domesticate species in the world and has been selectively bred over millennia for various behaviors, sensory capabilities, and physical attributes (Dewey and Bhagat, 2002). The family of dog is Canidae. Since there is very scanty literature on the comparative anatomy of scapula of Common palm civet cat (Paradoxurus hermaphrodites) and Dog (Canis lupus familiaris), being a schedule-II anima of wildlife and first domesticated animal of animal diversity. Hence, the present study was designed to established gross anatomical norms on the scapula of these animals.

\section{MATERIALS AND METHODS}

In the current investigation, the scapulas of thoracic limbs were collected from an adult Common palm civet cat (Paradoxurus hermaphrodites) and Dog (Canis lupus familiars) after death of the animal. The animal was died in road accident in the campus of College of Veterinary Science, Assam Agricultural University, Khanapara, Guwahati, Assam, India. After death of the animal was brought to the Department and the scapulas were processed as per the standard method of Young (1980) and gross anatomical studies were made on it.

\section{RESULT AND DISCUSSIONS}

The present study was conducted on one pair of scapula of Common palm civet cat (Paradoxurus hermaphroditus) and Dog (Canis lupus familiaris). The scapula of Common palm civet cat had two surfaces, three borders and three angles. These findings were in accordance with the findings of Pereira (2016) in carnivore. The two surfaces were lateral and medial. The lateral surface of scapula was divided by the scapular spine and formed supraspinous, and infraspinous fosse (Figure 1). The size of the fosse were larger compared to the fosse of scapula of Dog. The size of the rough area of the scapular spine was larger compared to the size of the rough area of the scapular spine of dog (Figure 2). The scapular spine divided the lateral surface of scapula into two equal half. These finding was total agreement with the finding of Sisson (1975) in carnivore. The sub scapular fosse of medial surface of the scapula of Dog (Canis lupus familiaris) was more deep compared to the scapula of Common palm civet cat (Figure 3). The rough lines of medial surface of the scapulas of Common palm civet cat were more prominent compared to the scapula of dog (Figure 4). Those rough lines were more prominent in scapula of Common palm civet cat due more attachment of muscle in the scapula. Those attachments help arboreal activity of the animal. The scapular index was less compared to the scapula of dog. The three border of the scapula of Common palm civet cat (Paradoxurus hermaphroditus) were vertebral border, cranial border and caudal border. The three angle of scapula were cranial, caudal and glenoid angle. The cranial angle of the scapula was formed by the vertebral border and cranial border 


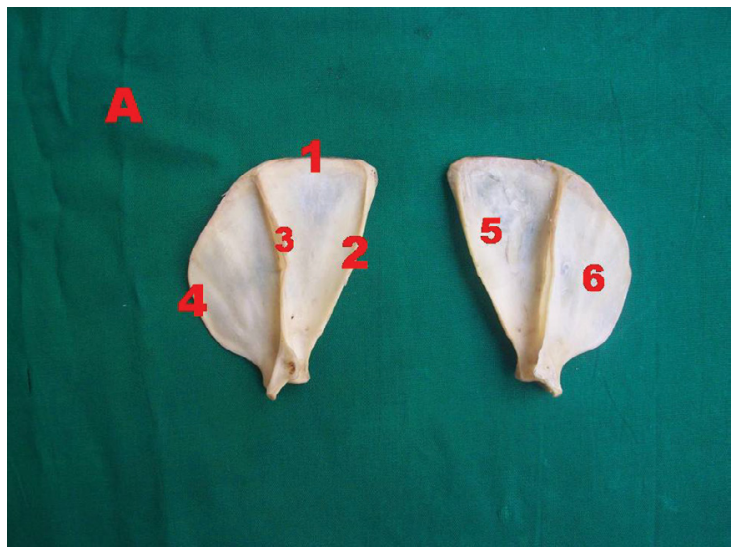

Figure 1: Photograph showing the lateral surface (A) dorsal border (1) caudal border (2) cranial border (4) rough area for the attachment of muscle (3) of scapula of Common palm civet cat (Paradoxurus hermaphroditus).

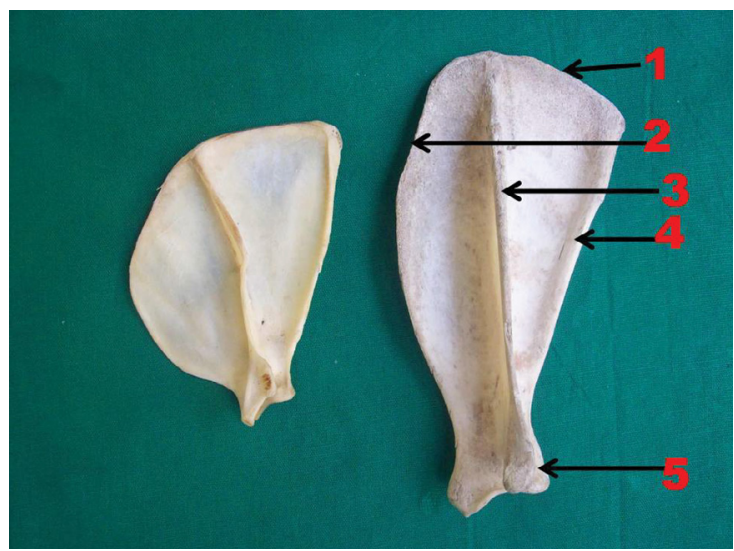

Figure 2: Photograph showing the vertebral border (1), cranial border (2), rough area of spine (3), caudal border (4) and acromion process (5) of scapula of dog (Canis lupus familiaris).

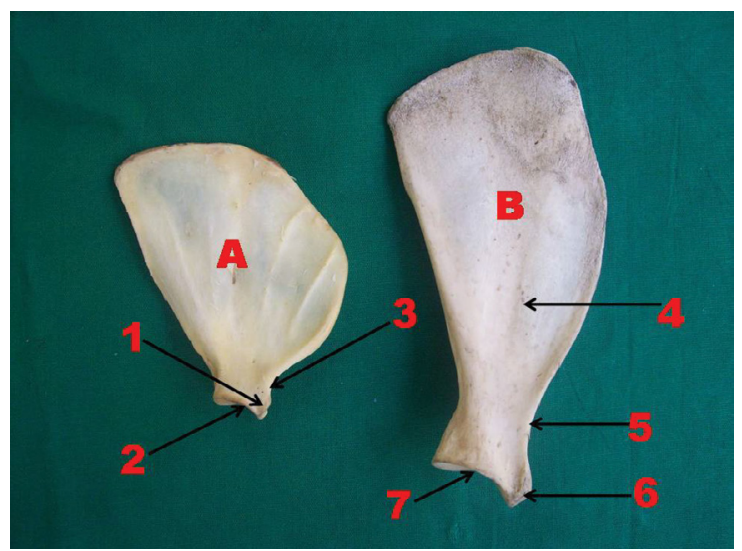

Figure 3: Photograph showing the tubercle (1), glenoid cavity (2), neck (3) of scapula of Common palm civet cat (Paradoxurus hermaphroditus) (A) and sub scapular fossa (4), neck (5), tubercle (6) and glenoid cavity (7) of scapula of Dog (Canis lupus familiaris).

where as caudal angle of the scapula was formed by the vertebral border and caudal border. The glenoid angle of the scapula were composed of supra glenoid tubercle, acromion process, glenoid notch, glenoid cavity and rim of the glenoid cavity (Figure 5). The depths of glenoid cavity and glenoid notch were more compared to the scapula of the dog. The necks of the scapula of Dog (Canis lupus familiaris) were less constricted compared to the scapula of Common palm civet cat (Paradoxurus hermaphroditus) (Figure 6).

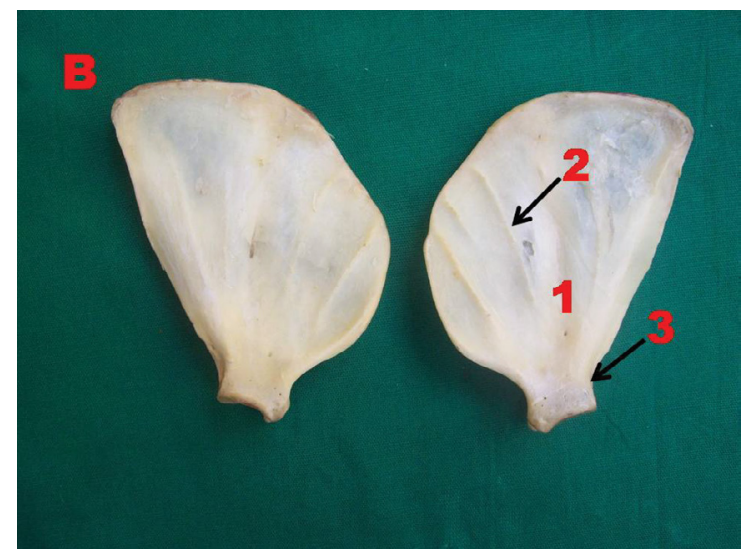

Figure 4: Photograph showing the medial surface $(B)$ rough line (2) sub scapular fossa (1) and neck (3) of the scapula of common palm civet cat (Paradoxurus hermaphroditus).

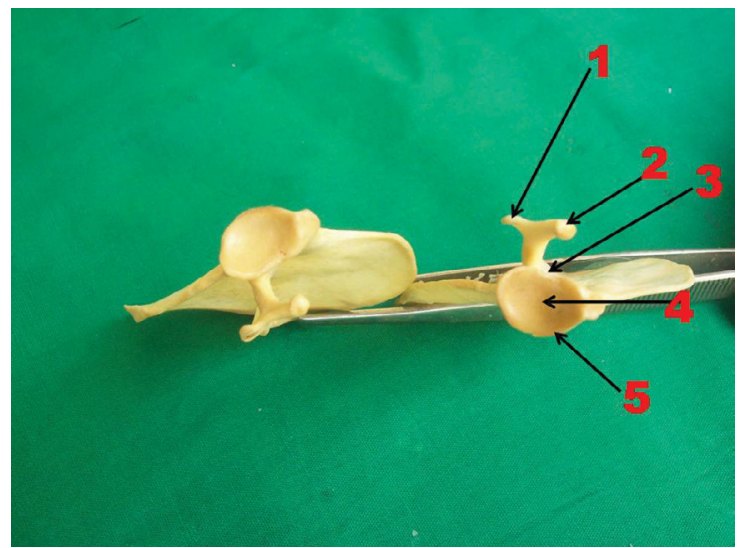

Figure 5: Photograph showing the supra glenoid tubercle (1), acromion process (2), glenoid notch (3), glenoid cavity (3) and rim of the glenoid cavity (5) of scapula of Common palm civet cat (Paradoxurus hermaphroditus).

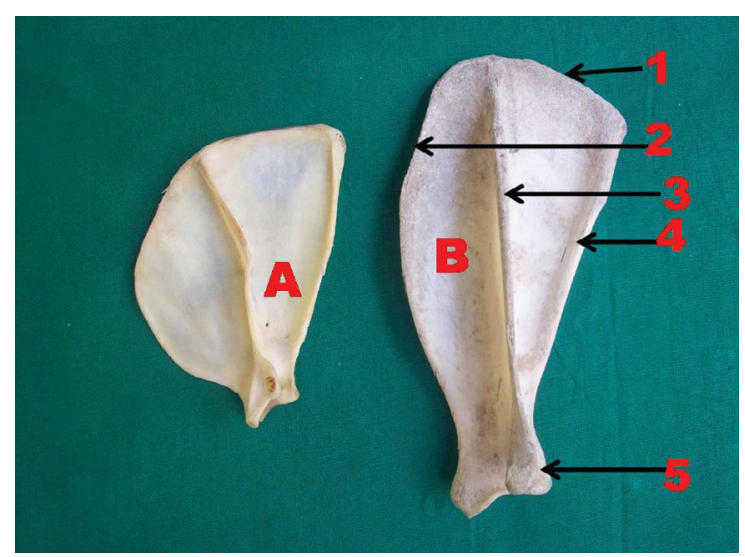

Figure 6: Photograph showing the scapula of Common palm civet cat (Paradoxurus hermaphroditus) (A) and Vertebral border (1), cranial border (2), rough area of spine (3), caudal border (4) and acromion process (5) of scapula of Dog (Canis lupus familiaris). 


\section{SUMMARY AND CONCLUSION}

In current study, the size of the supraspinous and infraspinous fosse were larger compared to the fosse of scapula of Dog. The size of the rough area of the scapular spine of Common palm civet cat was larger compared to the size of the rough area of the scapular spine of dog. The sub scapular fosse of the scapula of Dog (Canis lupus familiars) was more deep compared to the scapula of Common palm civet cat. The scapular index of Common palm civet cat was less compared to the scapula of dog. The depths of glenoid cavity and glenoid notch of scapula of Common palm civet cat were more compared to the scapula of the dog. The neck of the scapula of Dog (Canis lupus familiars) was less constricted compared to the scapula of Common palm civet cat (Paradoxurus hermaphroditus). The studies will be helpful to wildlife veterinarian to effective control the disease regime as well as veterolegal cases.

\section{ACKNOWLEDGEMENT}

The author is grateful to the Dean, Faculty of Veterinary
Science and HOD, Department of Anatomy \& Histology, College of Veterinary Science, Assam Agricultural University, Khanapara, Guwahati, Assam, India to carry out the research. The author is also grateful to the forest staff of Amusing wildlife sanctuary for the sample.

\section{REFERENCES}

1. Menon, V. 2003. A field guide to Indian mammals. $1^{\text {st }}$ Edn. London, New York, Melbourne, Muich, and Delhi., 106.

2. Dewey, T. and Bhagat, S. 2002. Canis lupus familiaris. Animal diversity web.

3. Pereira, S. G., Santos, A. L. Q., Borges, D. C. S., Queiroz, P. R. R. and Silva, J. O. R. D. 2016. Anatomia ossea e muscular da scapular bracoele chrysocyon brachyurus (Carnivora, Canidae). Ciene. anim. bras., Goiania, 17: 622-632.

4. Sisson, S. 1975. Carnivore osteology. Gety, Sissoon and Grossman, the Anatomy of the Domestic Animals. $4^{\text {th }}$ Edn. 2: 1437. 